\title{
“Espelho meu, espelho meu...” - Imagens das práticas nos ensinos básico e secundário
}

\author{
Isabel Barbosa, Celeste Pereira, Conceição Branco \\ Agrupamento de Escolas Sá de Miranda, Braga, Portugal
}

\begin{abstract}
Resumo
Nesta comunicação, apresenta-se uma experiência pedagógica levada a cabo no âmbito do projeto "Pedagogia para a autonomia e sucesso educativo que relação?”, em curso no Agrupamento de Escolas Sá de Miranda, em Braga, Portugal. A experiência consistiu na aplicação dum instrumento intitulado "Espelho meu, espelho meu...", para promover a tomada de consciência sobre a natureza do envolvimento dos alunos nas atividades letivas, facilitando o processo de regulação das práticas de aprendizagem e de ensino. Tratando-se de um instrumento simultaneamente de ensino e de desenvolvimento profissional, é apresentado em duas versões - uma na perspetiva do aluno e outra na do professor.

Palavras-chave: reflexão metacognitiva, avaliação processual, papéis pedagógicos, autorregulação, autonomia.
\end{abstract}

\section{Procurando imagens de autonomia}

O recurso à metáfora do espelho no âmbito da experiência pedagógica que aqui se apresenta assenta no pressuposto de que as ações dos diferentes agentes do processo educativo refletem a sua imagem enquanto detentores dos papéis que desempenham. Assim, a tomada de consciência das ações realizadas pelos intervenientes nesse processo promove o autoconhecimento, por sua vez indispensável à introdução das mudanças necessárias à melhoria dos respetivos desempenhos.

No âmbito do projeto em que esta experiência se enquadra, a mudança que se pretende operar é no sentido da promoção da qualidade dos processos de ensino e aprendizagem, através do desenvolvimento da autonomia de alunos e professores.

O reconhecimento da necessidade de promover a qualidade da educação está expresso em vários documentos reguladores emanados do Ministério da Educação, nomeadamente no documento orientador da revisão curricular do Ensino Secundário (Ministério da Educação, 2003), no qual se estabelece como objetivo estratégico: "o aumento da qualidade das aprendizagens, no respeito pela pluralidade e equilíbrio dos seus fundamentos, a saber: a aquisição de conhecimentos, o desenvolvimento das competências vocacionais, a capacidade de pensar cientificamente os problemas, a interiorização de uma cultura de participação e responsabilidade, a plena consciência das opções que potenciam a liberdade e o desenvolvimento dos alunos como indivíduos e como cidadãos.”
A este objetivo subjaz uma visão humanista e emancipatória da educação, da qual faz parte essencial “fazer o povo pensar” (Alves, 2000), isto é, desenvolver uma atitude crítica face à realidade, para agir em liberdade e responsabilidade. Trata-se, pois, de um objetivo assente num ideal educativo que não é de fácil operacionalização. Reconhecendo essa complexidade e amplitude, os autores do documento orientador da reforma do Ensino Secundário afirmam ter consciência "de que uma parte significativa desse processo de qualificação [das aprendizagens] passa por uma profunda mudança nos métodos de ensino e no ambiente da sala de aula” (Ministério da Educação, op. cit.).

Se a finalidade da educação é o desenvolvimento integral dos alunos, estes não podem continuar a desempenhar o papel de consumidores passivos do saber, devendo ter uma participação ativa e crítica na e face à sua construção (Vieira, 1998). A adoção duma pedagogia centrada na aprendizagem, conducente ao desenvolvimento da autonomia do aluno, será, deste modo, critério de qualidade educativa, pois proporcionando condições para o desenvolvimento da autonomia do aluno, definida por Holec (1981) como a capacidade de gerir a própria aprendizagem, a escola estará a contribuir para o desenvolvimento da capacidade de gerir outros aspetos da sua vida, e assim responder positivamente às exigências dum mundo em constante mudança.

Tendo por referência as finalidades educativas acima enunciadas, nas quais se incluem aspetos do desenvolvimento individual e da responsabilidade social dos sujeitos, com vista à construção duma sociedade livre e democrática, o desenvolvimento da autonomia na aprendizagem constitui-se como uma finalidade educativa assente nos direitos fundamentais do indivíduo (Benson, 2000). Partilhando a opinião de outros especialistas nesta área, como por exemplo Sinclair (2000), de que o desenvolvimento da autonomia é quase universalmente aceite como uma importante finalidade educativa, Benson (op. cit.) considera, contudo, que não são dadas aos alunos muitas oportunidades de exercer a autonomia na sua prática de aprendizagem. Explica este desfasamento com base numa conceção liberal humanista de aprendizagem como preparação para a vida, à qual contrapõe, na linha de pensamento de Dewey (1897), a perspetiva da teoria crítica, segundo a qual o processo de aprendizagem faz parte integrante da vida dos estudantes.

Defendendo esta visão de educação, concordamos com o autor, quando afirma que quanto mais cedo os 
alunos participem na tomada de decisões relativas à sua aprendizagem, mais capazes serão de vir a exercer a sua autonomia, o que encontra suporte em Little, Ridley, \& Ushioda (2002) quando expressam as suas crenças nas quais se apoiaram para levar a cabo um projeto de desenvolvimento da autonomia de jovens adolescentes, em escolas de nível pós-primário. Segundo estes autores, a autonomia não é um extra opcional, a desenvolver, ou não, conforme a preferência de cada professor. Pelo contrário, consideram que a autonomia é uma caraterística essencial dos alunos com sucesso, independentemente da idade ou do contexto de aprendizagem. Além do reforço da ideia de que o desenvolvimento da autonomia não deve depender das preferências dos professores, os autores explicitam também a relação de interdependência entre autonomia do aluno e do professor, afirmando que o desenvolvimento da autonomia do aluno requer que os professores mantenham uma atitude de questionamento face às suas crenças pedagógicas. Na sua opinião, um projeto que vise o desenvolvimento da autonomia dos alunos só será bem-sucedido se contribuir também para o desenvolvimento da autonomia dos professores envolvidos.

\section{O papel dos materiais didáticos}

A aceitação do princípio de que os materiais didáticos "constituem instrumentos de mediação entre o ensino $e$ a aprendizagem” (Vieira, 2006) parece justificar que sejam objeto de atenção privilegiada por parte dos professores, independentemente da abordagem pedagógica que defendam, para que não sejam formas de expressão dum currículo oculto, porventura em contradição com as teorias que perfilham.

No âmbito duma pedagogia para a autonomia, é inegável a sua importância no processo de ensino e aprendizagem, uma vez que fazem parte dum complexo conjunto de condições que podem facilitar ou inibir a sua operacionalização (Raya et al., 2007). Para que os materiais didáticos contribuam para o desenvolvimento da autonomia dos alunos, deverão ser construídos de acordo com o pressuposto de que não haverá aprendizagem sem o envolvimento ativo do aluno no ato de aprender (Nunan, 1997). E, para que os alunos possam desenvolver a capacidade de assumir a responsabilidade pela sua própria aprendizagem, será necessário que os materiais didáticos facilitem o desenvolvimento integrado de competências disciplinares e de aprendizagem, nas quais se incluem conhecimentos, atitudes e valores, capacidades e estratégias.

\section{Instrumentos de regulação das práticas}

A experiência que apresentamos desenvolveu-se em torno da aplicação duma lista de verificação elaborada pela primeira autora, durante a frequência da disciplina, lecionada por Flávia Vieira, Autonomia na Educação em Línguas: Implicações na Construção de Materiais de Ensino e de Formação, do curso de Mestrado/Especialização em Supervisão Pedagógica em Ensino das Línguas Estrangeiras (2007/2008). A sua elaboração emergiu da necessidade de promover a reflexão no seio da equipa envolvida no então recentemente criado projeto "Pedagogia para a Autonomia e sucesso educativo - que relação?”, um projeto multidisciplinar inserido no Plano Anual de Atividades da Escola Secundária Sá de Miranda, no ano letivo de 2007/2008 (ver Barbosa, 2009). Nessa fase do trabalho conjunto, a reflexão centrou-se essencialmente sobre os papéis pedagógicos desempenhados por alunos e professores no processo de ensino/aprendizagem, de forma a criar condições favoráveis ao desenvolvimento da autonomia dos alunos, e, consequentemente, à promoção do seu sucesso educativo. Existindo uma relação de implicação mútua entre os papéis pedagógicos de alunos e professores, partiu-se do pressuposto de que esta oportunidade de reflexão contribuiria também para o desenvolvimento da autonomia profissional dos professores envolvidos.

Tratando-se de um instrumento simultaneamente de ensino e de formação, é apresentado em duas versões uma na perspetiva do aluno e outra na do professor. Como primeiro passo para a sua elaboração, foi pedido a todos os elementos da equipa do projeto que enumerassem o que consideravam ser as características dum bom aluno, no que respeita a conhecimentos, atitudes e valores, capacidades e estratégias. Deveriam ainda tentar caracterizar os seus alunos, por referência a estes aspetos. O registo das conceções pessoais, bem como dos dados de observação dos alunos, constituiu o primeiro momento de reflexão num processo cujo objetivo era tomar consciência sobre teorias e práticas, de alunos e professores, relativamente a uma das dimensões centrais duma pedagogia para a autonomia.

Além de permitir esta reflexão, centrada nos alunos, e, por isso, menos "ameaçadora” para os professores com maior dificuldade em rever papéis pedagógicos tradicionalmente assumidos, o envolvimento dos colegas de equipa na construção deste instrumento assentou na convicção de que a democraticidade é um princípio central em qualquer processo de formação colaborativa. A partir do levantamento de todas as características recolhidas junto dos professores, foi possível reunir um conjunto de indicadores do tipo de envolvimento dos alunos nas atividades de sala de aula, o que deu origem a uma lista de 21 itens.

Versão do aluno. Na versão dos alunos (Figura 1), existe uma introdução cujo objetivo é consciencializálos sobre a importância da autoanálise no processo de desenvolvimento da sua autonomia: Para que te possas tornar um/a aluno/a cada vez mais autónomo/a, deves ter oportunidade de tomar consciência de vários aspetos do teu processo de aprendizagem. Hoje, proponho-te que centres a tua atenção na forma como te envolves nas atividades da aula, pois aquilo que fazes reflete o aluno que és. Assinala, na seguinte lista de verificação, as ações por ti realizadas em diferentes aulas. Que tipo de aluno vês no "espelho" da tua prática? Que aspetos podes melhorar?

Pretende-se, assim, sensibilizá-los para a mobilização deste instrumento numa série de três aulas, para que, ao fim de algum tempo, cada um veja nas suas ações o 
reflexo do aluno que é, o que lhe permitirá regular, de forma intencional e responsável, aspetos importantes do seu processo de aprendizagem.

\begin{tabular}{|l|}
\hline \multicolumn{1}{|c|}{ Nesta aula... } \\
\hline 1. fui pontual \\
\hline 2. trouxe o material necessário \\
\hline 3. estive atento/a \\
\hline 4. compreendi as atividades \\
\hline 5. participei com interesse nas atividades \\
\hline 6. tentei participar, mesmo cometendo erros \\
\hline 7. tomei notas por iniciativa própria \\
\hline 8. respondi a perguntas do/a professor/a \\
\hline 9. fiz perguntas ao/à professor/a \\
\hline 10. tentei resolver dúvidas com a ajuda do/a professor/a \\
\hline 11. tentei resolver dúvidas com a ajuda de colegas \\
\hline $\begin{array}{l}\text { 12. tentei resolver dúvidas usando materiais de apoio } \\
\text { (caderno, manual,...) }\end{array}$ \\
\hline 13. colaborei com os meus colegas \\
\hline 14. esforcei-me por aprender \\
\hline 15. relacionei a matéria nova com o que já sabia \\
\hline 16. aprendi coisas novas \\
\hline 17. refleti sobre a matéria \\
\hline 18. refleti sobre a forma como aprendo \\
\hline 19. avaliei o meu trabalho \\
\hline 20. avaliei o trabalho dos meus colegas \\
\hline $\begin{array}{l}\text { 21. dei a minha opinião sobre a aula/ fiz sugestões ao/à } \\
\text { professor/a }\end{array}$ \\
\hline
\end{tabular}

Figura 1: Lista de verificação para o aluno

À direita da coluna dos itens, existem três colunas, onde os alunos indicam as datas correspondentes às aulas em análise. Existem três hipóteses de resposta, expressas através dos seguintes símbolos: $\sqrt{ }$ (Sim); ? (Talvez/Nem sempre); X (Não). Existe ainda uma quarta coluna, para destaque dos aspetos a melhorar.

Versão do professor. Na introdução à versão dos professores (Figura 2), que funciona como uma folha de registo das respostas dadas pelos alunos, são colocadas algumas questões orientadoras de reflexão sobre essas respostas - $O$ que fizeram os alunos durante estas aulas? Quais as práticas mais recorrentes e mais ausentes? Os resultados globais correspondem à ideia que tenho da turma? O que me dizem sobre o papel dos alunos no processo de ensino/aprendizagem? Que factores determinam as práticas dos alunos? Em que medida as práticas de aprendizagem refletem as de ensino? Em que aspectos posso intervir, no sentido de promover um envolvimento mais ativo dos alunos no processo de ensino/aprendizagem? $\mathrm{O}$ uso deste instrumento não só permite caraterizar os alunos, em termos do seu envolvimento nas atividades letivas, mas também facilita a indagação crítica das práticas de ensino refletidas nas de aprendizagem. Além das colunas relativas aos três momentos de aplicação do instrumento, (subdivididas em três, para possibilitar o registo das diferentes opções de resposta), contém ainda uma quarta coluna, onde o professor assinala os aspetos em que pode intervir. Deste modo, esta lista de verificação pode ser utilizada pelo professor como um instrumento regulador das suas práticas, desde a fase da planificação das aulas. Na verdade, no que respeita a alguns itens, em particular os que envolvem reflexão metacognitiva ou auto e heteroavaliação, a participação ativa dos alunos depende da natureza das atividades propostas.

\begin{tabular}{|l|}
\hline \multicolumn{1}{|c|}{ Nesta aula, os alunos dizem que... } \\
\hline 1. foram pontuais \\
\hline 2. trouxeram o material necessário \\
\hline 3. estiveram atentos/as \\
\hline 4. compreenderam as atividades \\
\hline 5. participaram com interesse nas atividades \\
\hline 6. tentaram participar, mesmo cometendo erros \\
\hline 7. tomaram notas por iniciativa própria \\
\hline 8. responderam a perguntas do/a professor/a \\
\hline 9. fizeram perguntas ao/à professor/a \\
\hline 10. tentaram resolver dúvidas com a ajuda do/a professor/a \\
\hline 11. tentaram resolver dúvidas com a ajuda de colegas \\
\hline $\begin{array}{l}\text { 12. tentaram resolver dúvidas usando materiais de apoio } \\
\text { (caderno, manual,...) }\end{array}$ \\
\hline 13. colaboraram com os colegas \\
\hline 14. esforçaram-se por aprender \\
\hline 15. relacionaram a matéria nova com o que já sabiam \\
\hline 16. aprenderam coisas novas \\
\hline 17. refletiram sobre a matéria \\
\hline 18. refletiram sobre a forma como aprendem \\
\hline 19. avaliaram o seu trabalho \\
\hline 20. avaliaram o trabalho dos colegas \\
\hline $\begin{array}{l}\text { 21. deram a sua opinião sobre a aula/ fizeram sugestões } \\
\text { ao/à professor/a }\end{array}$ \\
\hline
\end{tabular}

Figura 2: Lista de verificação para o professor

\section{Contexto e metodologia}

Com a agregação da Escola Sá de Miranda com o Agrupamento de Escolas de Palmeira surgiu a oportunidade de alargar, no início do corrente ano letivo, a equipa do projeto em que esta experiência se enquadra. Na primeira reunião de trabalho do primeiro período, decidiu-se experimentar a aplicação deste material com alunos dos diferentes níveis de aprendizagem, com o objetivo de os consciencializar da importância de assumirem um papel ativo no processo de aprendizagem, uma vez que um dos objetos de reflexão da equipa tem sido a necessidade de promover a autonomia dos alunos, tanto quanto possível desde o início do seu percurso escolar. No Ensino Básico, estiveram envolvidos 20 alunos do $2 .^{\circ}$ Ciclo (5. ${ }^{\circ}$ ano), na disciplina de Matemática, e 18 do $3 .^{\circ}$ Ciclo (8. ano), na disciplina de Física e Química; no Ensino Secundário, obtiveram-se respostas de um total de 159 alunos de diferentes anos, turmas e contextos disciplinares (Inglês, Filosofia e Educação Física).

Depois de preenchidas as colunas referentes às aulas em que a lista de verificação foi utilizada, foi pedido aos alunos que assinalassem, na última coluna da grelha, os aspetos a melhorar. Acreditamos que este foi um momento importante de avaliação processual, uma vez que requereu uma reflexão crítica global sobre o seu grau de envolvimento em diferentes momentos do ano letivo. $\mathrm{Na}$ perspetiva das professoras envolvidas, as respostas dos alunos constituíram um importante objeto de reflexão e questionamento sobre as suas próprias práticas, no sentido de criarem condições facilitadoras 
duma participação mais ativa dos alunos nas atividades letivas.

\section{Apresentação e análise dos resultados}

Apresenta-se, de seguida (Tabela 1), uma síntese das respostas dos alunos, com base na qual será possível tirar algumas ilações sobre as imagens refletidas nos seus “espelhos". Optámos por apresentar os dados por níveis de aprendizagem, o que permitirá comparar as perceções dos alunos sobre o seu grau de envolvimento nas atividades, nos diferentes contextos de aplicação do instrumento.

Tabela 1.

Resultados globais, por nível de aprendizagem

\begin{tabular}{lccc}
\hline \multicolumn{1}{c}{ Itens } & $\begin{array}{c}\mathbf{\%} \\
\mathbf{2 .}^{\mathbf{0}} \mathbf{C i c l o}\end{array}$ & $\begin{array}{c}\mathbf{\%} \\
\mathbf{3 .}^{\mathbf{0}} \mathbf{C i c l o}\end{array}$ & $\begin{array}{c}\mathbf{\%} \\
\text { E. Sec. }\end{array}$ \\
\hline 1. Pontualidade & 85 & 77 & 89 \\
2. Material & 95 & 77 & 91 \\
3. Atenção & 80 & 38 & 94 \\
4. Compreensão & 80 & 88 & 91 \\
5. Interesse & 85 & 66 & 71 \\
6.Persistência & 65 & 50 & 75 \\
7. Iniciativa & 50 & 27 & 50 \\
8. Respostas & 55 & 61 & 69 \\
9. Perguntas & 35 & 55 & 55 \\
10. Ajuda prof. & 55 & 77 & 74 \\
11. Ajuda colegas & 35 & 83 & 73 \\
12. Mat. de apoio & 60 & 88 & 71 \\
13. Colab. colega & 60 & 83 & 85 \\
14. Esforço & 85 & 77 & 88 \\
15. Rel. conhecim & 70 & 66 & 77 \\
16. Novas aprend. & 85 & 88 & 87 \\
17. Refl. matéria & 50 & 44 & 77 \\
18. Refl. aprend. & 50 & 61 & 70 \\
19. Autoavaliação & 45 & 33 & 76 \\
20. Heteroaval. & 10 & 5 & 60 \\
21. Opinião & 20 & 16 & 45 \\
\hline
\end{tabular}

Não se tendo verificado variações, de aula para aula, que permitissem definir um padrão de evolução ao longo do tempo, decorrente do processo de reflexão metacognitiva associado à utilização da lista de verificação, optámos por apresentar valores percentuais que traduzem a média das respostas afirmativas, para cada item, recolhidas junto da totalidade dos alunos de cada contexto referido, nos três momentos de aplicação da lista de verificação.

Num primeiro nível de análise, os resultados obtidos permitem constatar que é no Ensino Básico (2. ${ }^{\circ}$ e $3 .^{\circ}$ Ciclos) que se verifica um maior número de itens com percentagens de respostas afirmativas abaixo dos 50\%.

Será, contudo, necessário identificar os itens que se destacam, tanto pela positiva (80\% ou mais) como pela negativa (abaixo dos 50\%), para se proceder a uma interpretação dos dados, por referência a uma imagem aproximada de autonomia.

Ensino Básico. No 2..$^{\circ}$ Ciclo, os valores mais elevados (entre $80 \%$ e 95\%) correspondem aos itens que revelam uma atitude positiva face à aprendizagem, essencialmente no que respeita à adoção de comportamentos adequados $(1,2,3)$, bem como compreensão e envolvimento nas atividades, vontade de aprender $(4,5,14)$ e concretização de novas aprendizagens (16). No 3. ${ }^{\circ}$ Ciclo, os valores mais elevados (entre $80 \%$ e $88 \%$ ) estão associados a itens relativos à compreensão das atividades (4), estratégias de aprendizagem (11 e 12), colaboração com os pares (13) e concretização de novas aprendizagens (16).

Os resultados obtidos revelam alunos com características diferentes, principalmente no que respeita às atitudes na sala de aula, verificando-se um contraste entre as percentagens relativas ao nível de atenção $80 \%$ dos alunos do $2 .^{\circ}$ Ciclo, contra $38 \%$ dos do $3 .^{\circ}$ Ciclo. Verifica-se, por outro lado, a tendência inversa no que respeita à tentativa de resolução de dúvidas com a ajuda de colegas - 35\% no 2 . $^{\circ}$ Ciclo, contra $83 \%$ no 3. ${ }^{\circ}$ Ciclo.

No que respeita às percentagens mais baixas, na turma do 2. ${ }^{\circ}$ Ciclo, destacam-se os itens relativos à interação com a professora e com os colegas (9 e 11), bem como os que se prendem com a avaliação dos trabalhos e emissão de opinião e/ou sugestões à professora (19, 20 e 21). As percentagens mais baixas incidem, também na turma do $3 .^{\circ}$ Ciclo, nestes três itens, e ainda no que se refere à reflexão sobre a matéria (17), à iniciativa para tomar notas (7) e à atenção na sala de aula (3).

Estes resultados refletem a dificuldade da maioria destes alunos em assumir um papel proativo no processo de ensino/aprendizagem, nomeadamente em aspetos como a reflexão sobre a sua aprendizagem e a auto e heteroavaliação.

Ensino Secundário. Como acima se refere, o número de itens com valores percentuais inferiores a $50 \%$ é significativamente menor entre os alunos do Ensino Secundário, pelo que, em certa medida, se poderá concluir que os resultados obtidos apontam para um nível satisfatório de envolvimento dos alunos no processo de aprendizagem. Contudo, agrupando os itens em que se obtiveram os valores mais elevados (entre $85 \%$ e 94\%), verifica-se que, à semelhança do que acontece com os alunos do Ensino Básico, se trata de itens relacionados com aspetos atitudinais (1, 2 e 3), bem como compreensão das atividades (4), colaboração com os colegas (13), vontade de aprender (14) e concretização de novas aprendizagens (16). É interessante verificar que é neste item que se obtém um maior consenso de respostas entre os alunos dos $2 .^{\circ}$ e $3 .^{\circ}$ Ciclos e Secundário (85\%, 88\% e 87\%, respetivamente).

No que respeita às percentagens mais baixas, destacase, como no Ensino Básico, a emissão de opiniões e/ou sugestões à professora (21) com 45\%, seguido da iniciativa para tomar notas (7), com 50\%, tal como no 2. ${ }^{\circ}$ Ciclo.Com base nos resultados obtidos, apresenta-se, de seguida, uma breve reflexão sobre a experiência, na perspetiva das autoras deste texto, explicitando-se os principais constrangimentos sentidos, bem como as limitações e potencialidades do trabalho realizado.

\section{Avaliação da experiência}

\section{Constrangimentos, limitações e potencialidades}

Apesar das diferenças identificadas entre as respostas dos alunos do Ensino Básico e do Ensino Secundário, os 
resultados obtidos revelam imagens semelhantes de autonomia, apresentando limitações e potencialidades comuns, que servirão de base para reflexão por parte das professoras envolvidas e de toda a equipa a que pertencem.

Como principais fatores de constrangimento sentidos pelas professoras da Escola EB 2/3 de Palmeira destacam-se os seguintes: 1. escassez de tempo disponível para desenvolver o projeto, 2. hábitos de trabalho de alunos e professores, 3. atitude passiva dos alunos, em termos de (auto)reflexão crítica e expressão de opiniões e 4. falta de formação específica sobre pedagogia para a autonomia.

Alguns destes constrangimentos, que resultam naturalmente da recente adesão destas colegas ao projeto em curso desde 2007, são também sentidos pelas professoras da Escola Sá de Miranda, em particular no que respeita ao tempo disponível para aprofundar a reflexão sobre os aspetos contemplados na lista de verificação. Na verdade, o facto de nem sempre ter sido possível criar momentos de reflexão imediatamente depois da aplicação do instrumento pode ter condicionado o impacto da experiência, tanto em termos de regulação das práticas de aprendizagem, como de ensino. Esta limitação poderá ter reduzido o grau de explicitação necessária à compreensão não só dos objetivos inerentes à reflexão sobre as práticas, mas também da natureza das atividades letivas e dos papéis assumidos durante a sua realização.

Apesar das fragilidades detetadas, as professoras envolvidas reconhecem a relevância da experiência, essencialmente por ter servido para alertar os alunos para a possibilidade de assumirem um papel mais ativo e responsável no contexto da sala de aula. Em relação aos alunos do Ensino Básico, as professoras destacam as seguintes potencialidades: 1 . os alunos perceberam que poderiam recorrer à ajuda uns dos outros, para resolver as suas dificuldades; 2. demonstraram maior à vontade para pedir ao professor o esclarecimento das suas dúvidas, assim como dar a sua opinião ou sugestões para o desenvolvimento do processo de ensino/aprendizagem e 3. em geral, entenderam o objetivo do projeto, considerando-o interessante, facilitador da reflexão sobre o seu trabalho e promotor de melhores desempenhos.

\section{Conclusão}

Pensamos que se cumpriu o principal objetivo da experiência, que era promover o autoconhecimento dos sujeitos envolvidos, para que possam controlar os fatores de constrangimento ao desenvolvimento da sua autonomia. Tendo em conta os aspetos atrás referidos, e o facto de a maioria dos alunos demonstrar interesse em continuar a trabalhar neste sentido, consideramos que se deve dar continuidade ao projeto no próximo ano letivo, se possível com as mesmas turmas, sendo a sua implementação contemplada na planificação das disciplinas, uma vez que o projeto faz parte do Plano Anual de Atividades.

A par dos aspetos centrados na aprendizagem dos alunos, será dada particular atenção à (auto)formação no seio da equipa do projeto, enquanto comunidade de aprendizagem profissional.

\section{Referências}

Alves, R. (2000). Por uma Educação Romântica. Brevíssimos Exercícios de Imortalidade. Vila Nova de Famalicão: Centro de Formação Camilo Castelo Branco.

Barbosa, I. (2009). Pedagogy for autonomy and educational success - what relation? A multidisciplinary school project. Independence (Newsletter of the IATEFL Learner Autonomy Special Interest Group), 45: 13-19.

Benson, P. (2000). Autonomy as a learner's and teacher's right. In B. Sinclair, I. McGrath \& T. Lamb (Eds.). Learner Autonomy, Teacher Autonomy: Future Directions (pp. 111-117). London: Longman/ British Council.

Dewey, J. (1897). My Pedagogic Creed. School Journal, Vol. 54, pp. 7780 http://dewey.pragmatism.org/creed.htm

Holec, H. (1981). Autonomy and Foreign Language Learning. Oxford: Pergamon Press.

Little, D., Ridley, J. \& Ushioda, E. (2002). Towards Greater Learner Autonomy in the Foreign Language Classroom. Dublin: Authentik.

Ministério da Educação (2003). Reforma do Ensino Secundário. Documento Orientador da Revisão Curricular. Ensino Secundário. Lisboa: Autor.

Nunan, D. (1997). Designing and adapting materials to encourage learner autonomy. In Phil Benson \& Peter Voller (Eds.) Autonomy and Independence in Language Learning (pp. 192-204). London: Longman.

Raya, M. J., Lamb, T. \& Vieira, F. (2007). Pedagogia Para a Autonomia na Educação em Línguas na Europa. Para um Quadro de Referência do Desenvolvimento do Aluno e do Professor. Dublin: Authentik.

Sinclair, B. (2000). Learner autonomy: the next phase? In B. Sinclair, I. McGrath \& T. Lamb (Eds.). Learner Autonomy, Teacher Autonomy: Future Directions (pp. 4-14). London: Longman/ British Council.

Vieira, F. (1998). Autonomia na Aprendizagem da Língua Estrangeira: uma Intervenção Pedagógica em Contexto Escolar. Braga: Centro de Estudos em Educação e Psicologia do Instituto de Educação e Psicologia da Universidade do Minho.

Vieira, F. (2001). (Org.). Cadernos 2 - Grupo de Trabalho - Pedagogia para a Autonomia. Braga: Departamento de Metodologias da Educação do Instituto de Educação e Psicologia da Universidade do Minho.

Vieira, F. (2006). (Org.). Cadernos 4 - Grupo de Trabalho - Pedagogia para a Autonomia. Braga: Departamento de Metodologias da Educação do Instituto de Educação e Psicologia da Universidade do Minho. 